\title{
Students' Perceptions on MOOCs: An Exploratory Study
}

\author{
Noa Aharony and Judit Bar-Ilan \\ Department of Information Science, Bar-Ilan University, \\ Ramat Gan, Israel
}

\author{
Noa.Aharony@biu.ac.il; Judit.Bar-llan@biu.ac.il
}

\begin{abstract}
MOOCs are open, online courses that use information technologies to enhance the learning experience and attract various people from the entire world. The current study uses the Technology Acceptance Model (TAM), as well as personal characteristics such as learning strategies, cognitive appraisal, and Kuhlthau's (1991) model of information seeking as theoretical bases for defining factors that may influence students adopting MOOCs in their learning process, as well as describe their feelings during the learning process. The study was conducted in Israel during the 2014 academic year, and used both quantitative and qualitative techniques and involved 102 students who participated in a MOOC as part of the requirements in an offline course. They were requested to keep study diaries. The quantitative analysis revealed that perceived usefulness (PU) and perceived ease of use (PEOU) have a major influence on the intention to enroll in a MOOC. PEOU can be increased by improving the current MOOC platforms. PU can also be improved by providing content that suits the students' needs. The qualitative analysis showed mood changes over time; the feelings of uncertainty were replaced by expressions of confidence. We found that students have different needs and expectations. Therefore, the MOOC's platforms should provide multiple options to accommodate these needs.
\end{abstract}

Keywords: MOOC, Technology Acceptance Model, learning strategies, cognitive appraisal

\section{Introduction}

Massive Online Open Courses (MOOCs) are online courses that attract various people from the entire world. They are defined as open, free, easily accessed, participatory and distributed courses (Pappano, 2012). Siemens (2013) suggests that MOOCs are a combination of innovations and use of technology that provide learning opportunities for vast number of individuals. Daradoumis,

Material published as part of this publication, either on-line or in print, is copyrighted by the Informing Science Institute. Permission to make digital or paper copy of part or all of these works for personal or classroom use is granted without fee provided that the copies are not made or distributed for profit or commercial advantage AND that copies 1) bear this notice in full and 2) give the full citation on the first page. It is permissible to abstract these works so long as credit is given. To copy in all other cases or to republish or to post on a server or to redistribute to lists requires specific permission and payment of a fee. Contact Publisher@InformingScience.org to request redistribution permission.
Bassi, Xhafa, and Caballe (2013) add that the power of MOOCs is based on the active engagement of huge numbers of self-organizing learners and on the connections they create using the course platform and other social interactions tools. Glance, Forsey, and Riley (2012) found that the main characteristics of MOOCs are: courses that include a large number of learners, online and open access, lectures conveyed as videos (8-12 
minutes) followed by formative quizzes, automated assessment that involves peer and/or selfassessment, and online forums and requests for peer help and discussion. Nan, Himanshu, Afroditi, Guillaume, Jan, and Dillenbourg (2014) suggest that students who take MOOCs courses prefer studying in groups as they feel more connected. Summing up, the unique features of MOOCs are: massiveness, openness, and peer assessment. However there are several drawbacks associated with MOOCs: because they involve many participants, often thousands (hence the "massive" in MOOC), the management of the course is quite complex and tutor involvement is limited to most critical tasks. In addition, it is not possible for the human instructor to review and grade all assignments, thus, they are usually either computer-graded or assessed by peers taking the course. Further, there is a high dropout rate, and only about $5 \%$ to $15 \%$ of participants finish the course (Daradoumis et al., 2013). Moreover, one should take into account plagiarism and security vulnerabilities (Miguel, Caballe, \& Proeto, 2013).

MOOC models are changing rapidly and Siemens (2013) distinguishes among xMOOCs, cMOOCs, and quasi-MOOCs. xMOOCs duplicate online the traditional model of an expert teacher and learners as knowledge consumers with video tutorials and graded tasks. cMOOCs focus on the connectivist pedagogical approach that considers knowledge as a networked state and learning as the process of creating these networks, using online and social tools. QuasiMOOCs pertain to web-based tutorials such as Open Educational Resources (OER), that are not courses and do not involve social interaction.

Several studies have examined the MOOC phenomenon. Christensen, Steinmetz, Alcorn, Bennett, Woods, and Emanuel (2013) explored who takes MOOCs and why by conducting an online survey among the participants of a specific course. They found that the student population tends to be young, well educated, employed and from developed countries. Students take MOOCs because they would like to advance in their present jobs and to satisfy their curiosity. Data from the University of Pennsylvania Graduate School of Education (2013) show that MOOCs have only few active users, that students' "engagement" falls off, particularly after the first two weeks of the course, and that only a few students finish the course. Several researchers have suggested frameworks aiming to improve and personalize management, delivery, efficiency and evaluation of MOOCs (Daradoumis et al., 2013; Grover, Franz, Schneider, \& Pea, 2013).

So far only a few studies addressed students' attitudes towards MOOCs. Joseph and Nath (2013) conducted a pilot study of 35 students regarding the attitudes towards informal online learning (taking part in a MOOC) as part of a regular academic course. The students filled in pre- and post-MOOC surveys. One of the questions that appeared both at the pre- and the post-survey was whether they plan to take a MOOC course on a topic of interest in the near future. In the precourse survey, only $11 \%$ answered 'yes', but the percentage increased to $66 \%$ in the post-course survey. An even smaller, qualitative study with 26 students was conducted by Carolan and Magnin (2013). The largest study that we were able to locate followed a MOOC run on Coursera on bioelectricity by Roger Barr from Duke University (Belanger \& Thorton, 2013). The students participating in the course filled in pre- and post-course questionnaires. There is no information on the number of respondents to the pre-course survey. The post-course survey was filled in by 105 students. The objective of the surveys was to understand motivations for enrolling (fun was a major motivation in the pre-course survey and general interest in the topic in the post-course survey); to learn about the students' course activities; their attitude towards bioelectricity - the topic of the course; their reported learning outcomes; and factors promoting and barriers to course completion. Some of these questions were open ended, and quotations supporting the claims are presented, while for the other questions, simple descriptive statistics is given. More recently, Alraimi, Zo, and Ciganek (2015) suggested that the intention to continue using MOOCs was influenced by the course's perceived reputation, perceived openness, perceived usefulness and user's overall satisfaction. Xu (2015), who investigated MOOCs in China, reported that students' inten- 
tions regarding MOOCs were affected by their subjective norms and by the perceived usefulness of the course. Lately, Zhou (2016) suggested that attitudes towards MOOCs and perceived behavioral control were major factors that influenced students' intentions to use MOOCs. Thus so far only a few studies tried to explore motivation to participate and to complete courses offered on MOOCs.

Due to the proliferation of MOOCs, it is essential to understand whether students are willing and ready to accept this new approach of learning where courses are massive and open and students' assessment is quite different, and if not, instructors and course designers should understand what obstacles students face, and how they can help them overcome them. In the current study we will try to understand how students perceive the MOOC phenomenon and how they feel when studying courses offered on the MOOC platform. In addition, we will focus on students' characteristics and attitudes in order to understand what influences positive attitudes towards learning in MOOCs. We believe that the research outcomes may contribute to an understanding of the variables that influence students' attitudes towards MOOCs.

The current study uses the Technology Acceptance Model (TAM), a well-known theory for explaining individuals' technology behaviors (Davis, 1989), as well as personal characteristics such as learning strategies (Marton \& Säljö, 1976a, 1976b), cognitive appraisal (Lazarus \& Folkman, 1984), Kuhlthau's model of information seeking (1991) and usability principles as theoretical bases from which we can predict factors that may influence students adopting MOOCs in their learning process, as well as describe their feelings during the learning process. The research questions of this study are:

(a) To what extent does the TAM explain students' attitudes towards future use of MOOCs?

(b) How do personal characteristics such as learning strategies and cognitive appraisal influence students' attitudes towards future use of MOOCs?

(c) Do demographic variables such as gender and education affect students' attitudes towards future use of MOOCs?

(d) To what extent does Kuhlthau's model of information seeking explains students' emotional attitudes when studying courses offered on the MOOC platform?

\section{Theoretical Background}

\section{Technology Acceptance Model}

Adopting information technology has been the focus of many studies in information system research (Burton-Jones \& Hubona, 2005). The goal of technology acceptance theory is to understand the factors that influence adoption of new technologies throughout a social system (Barnes \& Huff, 2003), assuming that people can choose whether or not to adopt an innovation (Gefen \& Straub, 1997). The current research addresses the Technology Acceptance Model (TAM), which was developed by Davis (1989). The TAM is built on the Theory of Reasoned Action (TRA) that has its roots in social psychology. According to TRA, behavior is explained by people's behavioral intentions, attitudes, subjective norms, and beliefs (Fishbein \& Ajzen, 1975). Davis (1989) has introduced the TAM to study user acceptance of information systems. He suggests that the process of accepting information systems includes two major components: perceived usefulness (PU) and perceived ease of use (PEOU). PU addresses the notion that adopting a certain technology or system will contribute to a better performance. PEOU relates to the belief that there would be no difficulties in using the new technology or system (Davis, 1989).

Through the years, TAM was examined by researchers in various areas, including e-learning. AlBusaidi (2013) investigated learners' adoption of blended learning, finding that personal innovativeness and PU of the Learning Management System (LMS) are significant to learners' intention 
to engage in full e-learning. Another study that examined e-learning system usage in the university context revealed that PU and PEOU influence students' perceptions that the e-learning system will assist them in the learning process and in building a social community (Islam, 2013). In a recent survey (Cheung \& Vogel, 2013) focused on an extension of the TAM for e-learning and found that the traditional components of the TAM are the major factors that influence the adoption of Google Applications for collaborative learning. Recently Xu (2015) noted that intentions to use MOOC were associated with perceived usefulness (PU) of the course and not with its ease of use (PEOU). In light of the above, the first two research hypotheses will be:

H1: PU will be positively associated with future intended use of MOOCs.

H2: PEOU will be positively associated with future intended use of MOOCs.

\section{Learning Strategies}

The second variable that might affect IS students' attitudes towards MOOCs is learning strategies. Individual differences in intentions, motives and processing strategies used by students in different learning environments were explored in previous studies (e.g., Prat-Sala \& Redford, 2010). The current paper explores the deep learning versus the surface learning approach; terms that are based on the early work of Marton and Säljö (1976a, 1976b), who used qualitative analysis to examine differences in students' approaches towards written texts. In general, deep learners tend to explore the topic to its greatest extent (von Stumm \& Furnham, 2012). A deep learning strategy is usually followed by success, high quality learning outcomes (Trigwell \& Prosser, 1991), elaborating ideas, problem solving, critical thinking and self-management (Biggs, 1987; Kember, Charlesworth, Dabies, Mackay, \& Scott, 1997). It is associated with linking and integrating one concept with another (Biggs, 1987), as well as with students' intention to fully understand the text, concentrate on different aspects of the material, and seek relevant links between the new material, everyday life, and personal experiences. Deep learners tend to seek for their 'inner self' through the learning process (Biggs, 1993; Entwistle, 1977).

Contrarily, surface learners learn only important and essential facts, applying minimum study efforts (Biggs, 1987). A surface learning approach is associated with students who study only superficial details (Prat-Sala \& Redford, 2010). They are concerned with the time needed to accomplish the learning task; therefore, they try to choose the quickest way to accomplish their learning assignment, without asking further questions and without fully understanding the text meanings. Surface learners usually memorize facts, thus, meta-cognitive skills are mostly not involved in their learning process (Biggs, 1993).

It was shown that that a deep learning strategy leads to better grades, while a surface learning strategy is usually followed by lower grades (Duff, 2004; Ellis, Goodyear, Brillant, \& Prosser, 2008; Ellis, Goodyear, Calvo, \& Prosser, 2008). A previous study that focused on IS students showed that those students who exercise deep learning strategies have higher motivations towards learning about Web 2.0 applications and environments, and make greater use of them than do surface learners (Aharony, 2009). Yang and Tsai (2010) showed that deep learners were able to improve their achievements more in a multi-stage online peer assessment activity than their surface counterparts. Assuming that deep and surface learning strategies may predict students' MOOC future use, the hypotheses of this study are:

H3: Deep learning strategy will be positively associated with future intended use of MOOCs.

H4: Surface learning strategy will be negatively associated with future intended use of MOOCs. 


\section{Cognitive appraisal: Threat versus challenge}

Cognitive appraisals of threat and challenge refer to "dispositions to appraise ongoing relationships with the environment consistently in one way or another" (Lazarus, 1991, p. 138). Cognitive appraisal addresses the person's evaluation of events for his or her well-being (Lazarus, 1993). Lazarus and Folkman (1984) propose that when someone confronts a situation that threatens an important action, he or she undergoes a specific cognitive process. The person evaluates the demands of the environment ("primary appraisal"), and then chooses one of his/her resources to cope with the situation ("secondary appraisal"). A challenge appraisal indicates that the demands of the stressful situation can be overcome, and that the individual assumes that there is a potential for gain or benefit (Lazarus, Kanner, \& Folkman, 1980; Park \& Folkman, 1997). Lazarus suggests (1991) that the emotions associated with challenge are joy, excitement and happiness. In addition, these persons consider the possibility for success, social rewards, mastery, learning, and personal growth (Lazarus, 1991; Lazarus \& Folkman, 1984). Contrarily, threat occurs when the individual estimates that resources do not meet situational demands. Further threat is accompanied by potential danger to the person's self-esteem and self-being (Lazarus, 1991; Lazarus \& Folkman, 1984). Studies reveal that people who are in a threat state, experience anxiety in social or stressful situations, such as tests or sports and anticipate failure or negative evaluations (Rapee \& Heimberg, 1997; Wilson \& Eklund, 1998). Researchers suggest that challenge and threat are context bound and take place only in motivated performance situations such as delivering a speech, exams, or sport competitions (Blascovich, 2008; Blascovich, Mendes, Hunter, \& Lickel, 2000). Moreover, different studies show that a challenge state helps performance while a threat state slows it down (Mendes, Blascovich, Hunter, Lickel, \& Jost, 2007; Seery, Weisbuch, Hetenyi, \& Blascovich, 2010). Other studies that were conducted in the information science environment revealed that the more challenged information professionals are, the higher their behavioral intention to use e-books (Aharony, 2014a), and the higher is their Web 2.0 use (Aharony,2009). Based on the literature review, H5 and H6 are developed:

H5: High level of challenge will be positively associated with future intended use of MOOCs.

H6: High level of threat will be negatively associated with future intended use of MOOCs.

\section{Kuhlthau's model of the information seeking process}

Kuhlthau's model (1991) of the information seeking process emphasizes the emotional aspects of the information seeking process. Initially the individual feels uncertain when she understands that she lacks knowledge. This feeling of uncertainty is replaced by optimism when the user manages to select the topic or approach to be pursued. During the search process the individual experiences an "affective roller coaster", when uncertainty, confusion, clarity, confidence, satisfaction and/or dissatisfaction accompany the different phases of the search process.

In the current study our users, similarly to the high school students observed by Kuhlthau gathering information for their projects, experienced mood changes during the learning process.

\section{Usability}

Usability is a major concept of human computer interaction (HCI) (de Lera, Fernandez, \& Valverde, 2010; Preece, Rogers, \& Sharp, 2002; Rozanski \& Haake, 2003). There are several definitions to usability. According to Berns (2004), usability is "the extent to which a product can be used by specific users to achieve specified goals with effectiveness, efficiency and satisfaction in a specified context of use" (p.21). Nielsen (1993) proposes that usability refers to interface characteristics that are easy to learn, remember, and that are pleasant to use, efficient and generate the 
least errors. Nokelainen (2006) expanded Nielsen's definition and included pedagogical aspects in it, suggesting that usability aims at supporting the learning process. Various researchers found that usability is a main factor in adopting LMS for students as well as for instructors (Lewis et al., 2005; Mastoras, Fotaris, Politis, \& Manitsaris, 2005; de Porto Alegre Muniz \& de Moraes, 2012; Pretorius \& van Biljon, 2010). The current study will examine students' opinions about MOOCs' usability.

\section{Methodology}

\section{Data Collection}

This study was conducted in Israel during the first semester of the 2014 academic year. The students study in the Library and Information Science Department, at Bar-ilan University. There are several platforms of MOOCs: Coursera, edX, and Udacity. In the present study, students who participated in the Introduction to Information Science course were requested to sign up to the Human Computer Interaction (HCI) course on Coursera taught by Scott Klemmer from UC San Diego (see https://www.coursera.org/course/hciucsd). Courses on Coursera are of the xMOOC type (Siemens, 2013). This was a nine week long course, but the students had to take part only in the first four weeks of the course. In the first four weeks basics, the history of HCI, data collection methods, prototyping and heuristic evaluation were discussed. During these four weeks the students had to answer one multiple-choice and one peer-graded assignment and had to participate in the peer-grading process. The content of the first four weeks of the course were part of the offline course requirements. A short review of the major points covered in the online course was also given in the offline course.

The students were required to keep study diaries and answer the following guiding questions each week:

- What is your opinion on the course platform? Discuss pluses and minuses.

- What is your opinion about your learning process? Please relate both to cognitive and affective aspects. Discuss plusses and minuses.

- What is your opinion about the content of the course and the way it is being taught? Discuss plusses and minuses.

They were also asked about their opinions on the quiz, the assignment and on the peer-grading process (both about the way they rated the works of others and about the grade and comments they received from others). Finally, after four weeks of taking part in the MOOC, they were asked to compare this course to other online and offline courses they took and they were asked whether they were interested in taking other MOOCs in the future.

In addition, after four weeks of participating in the MOOC, researchers wanted to have a broader and a more comprehensive perspective about students' perceptions on MOOCs. Hence, students were asked to fill in a questionnaire comprised of: demographic data, a threats and challenges questionnaire, a deep vs surface learning questionnaire and a TAM questionnaire.

Altogether 102 students answered the questionnaire, and 96 of them answered the future use question in the diary. Future use was an open ended question, and was coded by us as: yes, depends and no. 


\section{Measures}

\section{Qualitative Research}

We used open questions to gather information about the process students have undergone while studying with the MOOC. In order to analyze the answers, we used a content analysis. The goal of content analysis is to examine message characteristics in an objective manner by applying consistent criteria rigorously (Neuendorf, 2002). Krippendorff (1980) presents the advantages of content analysis: it is unobtrusive, accepts unstructured material, and is context sensitive. It can also process symbolic forms and cope with large amounts of data. While analyzing the content of the diaries, special emphasis was placed on the affective aspects, usability issues and on their intention to taking MOOCs in the future. The data was collected and analyzed by the two researchers. The initial coding scheme was developed after the analysis of about $10 \%$ of data. The final percentage of agreement for all coding decisions was $90 \%$, which suggests that the coding classification used was reliable.

\section{Quantitative Research}

We used five questionnaires to gather the following data: personal details, cognitive appraisal, learning strategies, and two MOOC attitude questionnaires. The personal details questionnaire had three statements: gender, education and age.

The cognitive appraisal questionnaire measured students' feelings of threat versus challenge when confronted with new situations. It consisted of 9 statements rated on a 5-point Likert scale ( $1=$ strongest disagreement; $5=$ strongest agreement). This questionnaire was previously used (Aharony, 2009, Yekutiel, 1990) and consisted of two factors: threat (items 1, 2, 3, 4, 6, 7) and challenge (items 5, 8, 9). Cronbach's Alpha was .91 for the threat factor and .74 for the challenge factor.

The learning strategies questionnaire consisted of 14 statements rated on a 5-point Likert scale ( 1 =strongest disagreement; $5=$ strongest agreement). This questionnaire, which was also previously validated (Aharony, 2009, 2014b), consists of two factors: deep and surface learning strategies, with seven items for deep learning (items 1, 3, 6, 8, 9, 12, 13); and seven for surface learning (items 2, 4, 5, 7, 10,11, 14). Cronbach's Alpha coefficients were .78 and .71, respectively.

The first attitude questionnaire addressed MOOCs' perceived usefulness (PU) and was based on Liu, Li, and Carlsson (2010). It was modified for this study and consisted of three statements rated on a 5-point Likert scale ( $1=$ strongest disagreement; $5=$ strongest agreement). The value of Cronbach's Alpha was .83.

The second attitude questionnaire examined MOOCs' perceived ease of use (PEOU) and was also based on Liu, Li, and Carlsson (2010). It was modified for this study and consisted of three statements rated on a 5 -point Likert scale ( $1=$ strongest disagreement; $5=$ strongest agreement). The value of Cronbach's Alpha was .82. The questionnaires appear in the Appendix.

\section{Data Analysis}

\section{Quantitative Analysis}

Of the whole group, $36(35.29 \%)$ respondents were male and $66(64.70 \%)$ were female. Their average age was 28.58; where 59 (57.84\%) were Bachelor of Arts (BA) students and 43 (42.15\%) were Master of Arts (MA) students. In order to examine whether there are differences between BA and MA students concerning the study variables (cognitive appraisal, learning strategies, attitudes, and future use), a one-way MANOVA was conducted. The MANOVA revealed significant 
differences between the two groups concerning threat and challenge, $F(2,99)=6.22, p<.01, \eta^{2}$ $=.12$, and concerning deep and surface learning, $F(2,99)=11.73 p<.001, \eta^{2}=.19$. Means and standard deviations are presented in Table 1.

Table 1. Means and standard deviations of threat, challenge, deep and surface learning

\begin{tabular}{|l|r|r|r|r|r|r|}
\hline \multicolumn{1}{|c|}{ Measures } & \multicolumn{2}{|c|}{ BA Students } & \multicolumn{2}{c|}{ MA Students } & \\
\hline & $M$ & $S D$ & $M$ & $S D$ & $F(2,99)$ & $E t a^{2}$ \\
\hline Threat & 2.01 & .86 & 1.54 & .73 & $8.45^{* * *}$ & .07 \\
\hline Challenge & 2.81 & .87 & 3.27 & .82 & $6.96^{* *}$ & .06 \\
\hline Deep & 3.05 & .76 & 3.53 & .58 & $11.82^{* * *}$ & .10 \\
\hline Surface & 2.27 & .61 & 1.75 & .54 & $19.65^{* * *}$ & .16 \\
\hline
\end{tabular}

$* * \mathrm{p}<.01 ; * * * \mathrm{p}<.001$

Table 1 shows that the ANOVA performed on each measure separately revealed significant differences between the two groups concerning the four measures: threat and challenge, and learning strategies. It seems that BA students are more threatened than MA students of MOOC, and that MA students are more challenged than BA students participating in a MOOC. Further, MA students are deeper learners than BA students who are more surface learners. A further one-way MANOVA that focused on the TAM variables (PEOU, and PU) and MOOC future use, revealed a significant difference between the two groups concerning PU, $F(3,92)=2.69, p=.05, \eta^{2}=.08$. The ANOVA performed on each measure separately showed significant differences between the two group concerning PU, $F(1,94)=7.11, p<.01, \eta^{2}=.07$. It seems that MA students perceive MOOC as more useful, $M=3.64, S D=.88$, than BA students, $M=3.14, S D=.92$ (the variables were assessed on a scale of 1 to 5).

In order to examine the relationship between the demographic variables, PU, PEOU, learning strategies, cognitive appraisal, and MOOC future use, Pearson correlations were computed, which are given in Table 2 .

Table 2. Pearson correlations between demographic variables. PU, PEOU, learning strategies, cognitive appraisal, and MOOC future use $(\mathrm{N}=102)$

\begin{tabular}{|c|c|c|c|c|c|c|c|c|}
\hline Measures & Age & Education & $\mathbf{P U}$ & PEOU & Deep & Surface & Threat & Challenge \\
\hline \multicolumn{9}{|l|}{ Age } \\
\hline Education & $.66^{* * * *}$ & & & & & & & \\
\hline PU & .13 & $.22 *$ & & & & & & \\
\hline PEOU & .13 & .14 & $.50 * * *$ & & & & & \\
\hline Deep & $.31 * *$ & $.32 * *$ & $.24 *$ & .19 & & & & \\
\hline Threat & $-.24 *$ & $-.39 * * *$ & -.17 & .02 & $-.44 * * *$ & & & \\
\hline Surface & $-.23 *$ & -.29 & $-.50 * * *$ & $-.54 * * *$ & -.16 & .11 & & \\
\hline Challenge & .18 & $.25 * *$ & $.59 * * *$ & $.33 * *$ & .15 & .00 & $-.29 * *$ & \\
\hline Future use & .12 & $.22 *$ & $.38 * * *$ & $.24 *$ & .06 & -.04 & $-.21 *$ & .16 \\
\hline
\end{tabular}

$* p<.05 ; * * p<.01 ; * * * p<.001$ 
Significant positive correlations were found between PU, PEOU, education and future use; therefore, the higher level of PU and PEOU, and the higher students' academic degree, the higher MOOC's future use will be. Further, significant negative correlation was found between threat and future use. In other words, the less threatened students are, the higher their intention to participate in MOOCs in the future will be. Regarding the correlations between the research variables themselves, significant positive correlations were found between age and deep learning strategy, and significant negative correlations were found between age and surface learning strategy, and threat. In other words, the older students are, the more deep learners they are, and the less threatened they are of MOOC. Addressing the education variable, significant positive correlations were found between education and PU, deep learning strategy, and challenge, and significant negative correlation with surface learning strategy. It seems that the more educated students are deeper learners, more challenged and rate higher the usefulness of MOOCs.

We also conducted a hierarchical regression using MOOC future use as a dependent variable. The predictors were entered in five steps: (1) students' education; (2) cognitive appraisal variables (threat versus challenge); (3) learning strategies (deep and surface); (4) attitudes variables (PEOU, PU); and (5) interaction between deep learning strategy X PEOU. The entrance of the four first steps was forced, while the interaction was done according to its contribution to the explained variance of MOOC use. The regression explained 25\% of MOOC use. Table 3 presents the standardized and unstandardized coefficients of the hierarchical regression of respondents' MOOC future use.

Table 3. Hierarchical regression coefficients of students' MOOC future use ( $N=96)$

\begin{tabular}{|c|c|c|c|c|}
\hline Predictors & B & $\bar{\beta}$ & $\mathbf{R}^{2}$ & $\Delta \mathrm{R}^{2}$ \\
\hline 1. Education & .31 & $.19 *$ & $.04 *$ & $.04 *$ \\
\hline $\begin{array}{ll}\text { 2. } & \text { Threat } \\
\text { Challenge }\end{array}$ & $\begin{array}{r}-.15 \\
.07\end{array}$ & $\begin{array}{r}-.15 \\
.07\end{array}$ & $.03 *$ & .03 \\
\hline $\begin{array}{l}\text { 3. Deep } \\
\text { Surface }\end{array}$ & $\begin{array}{r}-.00 \\
.06\end{array}$ & $\begin{array}{r}-.00 \\
.04\end{array}$ & $.07 *$ & .00 \\
\hline $\begin{array}{l}\text { 4. } \\
\text { PEOU } \\
\text { PU }\end{array}$ & $\begin{array}{l}.07 \\
.36\end{array}$ & $\begin{array}{l}.08 \\
.41 * *\end{array}$ & $.18^{*}$ & $.11 * *$ \\
\hline 5. Deep X PEOU & -.20 & $-.28 * *$ & $.25 * *$ & $.07 * *$ \\
\hline
\end{tabular}

The first step introduced the education variable that contributed significantly by adding $4 \%$ to the explained variance of MOOC future use. The beta coefficient of the education variable is positive; hence, the more educated respondents are, the higher their intention to use MOOCs. The second step introduced the cognitive appraisal variables (threat versus challenge) of which only threat contributed significantly by adding 3\% to the explained variance of MOOC future use. The beta coefficient of threat was negative. In other words, the more threatened students are, the less their MOOC future use will be. The third step introduced learning strategies variables (deep and surface) that did not contribute to the explained variance of MOOC future use. The fourth step added students' perceptions about PEOU and PU that added $11 \%$ to the explained variance of MOOC future use. It should be noted that only the PU contributed significantly to the explained variance of MOOC future use. Therefore we may conclude that the more students perceive MOOC as useful, the higher their future intention to use it. As the fifth step, the interaction between deep learning strategy X PEOU was entered which added $7 \%$ to the explained variance of MOOC future use. The interaction between deep learning strategy and PEOU is presented in Figure 1. 


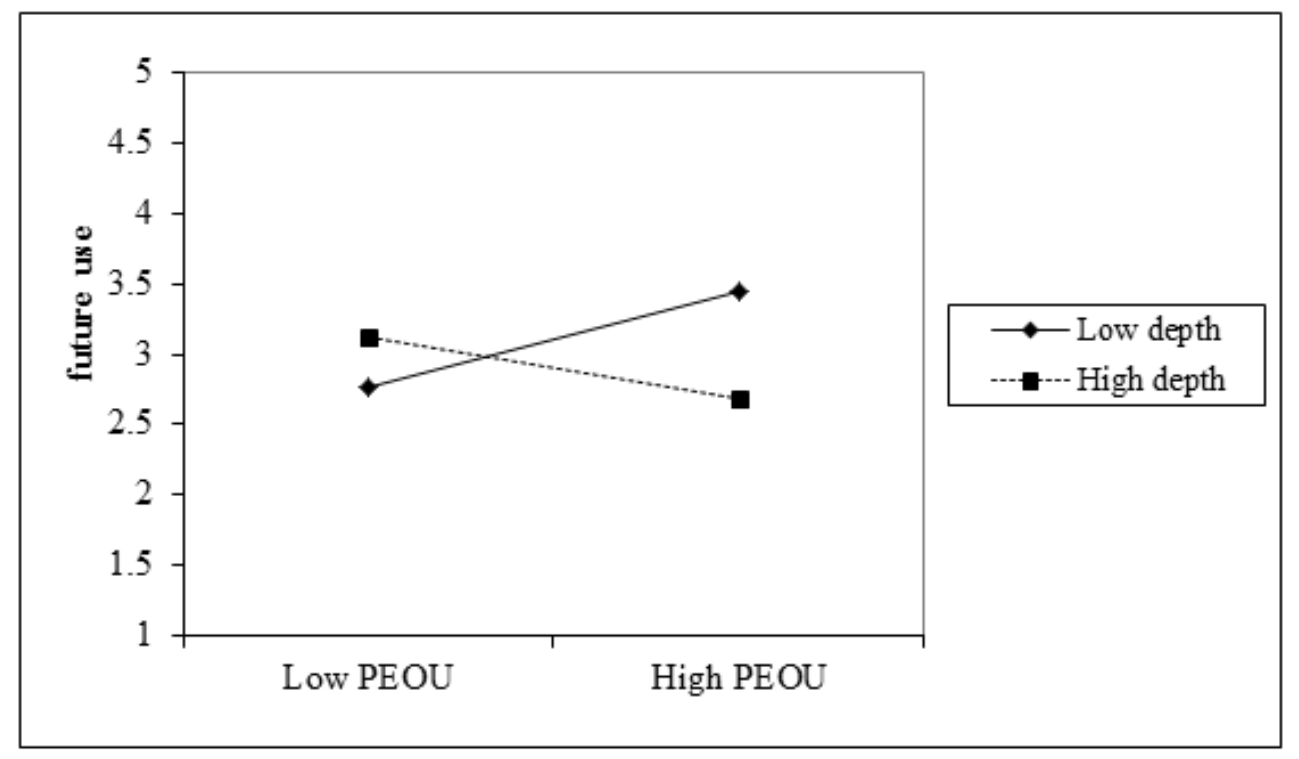

Figure 1. Interaction between deep learning strategy and PEOU

Significant correlation was found between perceived ease of use (PEOU) and MOOC future use among those students who are low in their deep learning strategy, $\beta=.29, p<.05$. However, no significant correlation was found between those students who are high in depth learning strategy and MOOC future use, $\beta=-.08, p>.05$. Thus, especially among students who are low on deep learning strategies, the higher they perceive MOOC's PEOU, the greater their MOOC future use will be.

\section{Qualitative Analysis}

The second section of the discussion will present the qualitative analysis that focused on emotional aspects while studying with the MOOC and on the students' opinions about MOOCs' usability. Based on Kuhlthau's model (1991), we found that students have undergone emotional changes over time. Some students wrote in their diaries that at the beginning of the course they felt uncertainty, confusion and did not know how to handle the new situation. A few quotations are presented below:

- "At the beginning of the course I felt confused"

- "At the beginning of the course I was excited and a bit scared"

- At first I felt uncertain about the course and its goals"

- "I felt stressed at the beginning"

- "I had the feeling of disorientation..."

Another dimension of uneasiness is presented by a student:

- "I was scared of the peer review process"

However, in accordance with Kuhlthau's model (1991), it seems that during the learning process the feelings of uncertainty diminished and were replaced with feelings of confidence. The following statements express this shift of feelings:

- "I got used to the platform, and I feel much better"

- "I felt uncertain at the beginning, but during the process I felt much more confident"

- "There is a process of adoption"

- "Over time, I became more relaxed" 
Students wrote that one cause to their feelings of uncertainty was the fact that the course was given in English, a foreign language to the Israeli students. Some of them wrote:

- "I had difficulties with the language"

- "I was frustrated because the course was in English"

However, we can see that again according to Kuhlthau's model (1991), this feeling has changed during the course and students' feelings got better:

- "During the course the level of English has improved"

- "I am proud that I have overcome the language difficulties"

Addressing the usability issue, there was not a consensus among the students. Some reported high satisfaction with the course platform while others were not satisfied with it. The following statements express satisfaction with the platform:

- "The interface was friendly and convenient "

- "The platform was very friendly"

- "There were many examples that facilitated the learning process"

- "There were short videos that helped understanding the material"

- "We could repeat and watch the lecture again and again"

- "The questions in the middle of the videos help me concentrate"

On the other hand, those students that were not satisfied with the MOOC stated:

- "There were many technological problems with the course"

- "The examples were not clear"

- "The fact that the course was given in English caused a lot of problems"

- "The questions during the videos distract me"

- "It is difficult and boring to sit alone by the computer and to watch the videos"

- "We lacked interaction with the instructor"

- "The videos were too long, they also got stuck in the middle"

\section{Discussion and Conclusions}

The first section of the discussion will be based on the quantitative analysis. The present research explored the extent to which the TAM, personal characteristics such as learning strategies, threat, and challenge, and demographic variables such as education, explain students' future intentions to use MOOCs in their learning process. By addressing these questions, this article makes a number of theoretical and practical contributions:

- It expands the current research about TAM by examining it within the context of MOOCs, focusing on the perspectives of students.

- It confirms that the TAM, as well as other personal and demographic characteristics, significantly predicts the likelihood of MOOCs adoption. Perceived usefulness contributes greatly to the intended future use of MOOCs.

- It highlights the importance of individual characteristics when considering technology acceptance. Instructors should be aware of individual differences in technology use and acceptance, as these factors may explain why some students adopt technological innovations in their study environments while others do not.

Addressing the study hypotheses, three of the six hypotheses were accepted. The first two (H1 and H2) support the TAM, suggesting that the more students perceive MOOCs as useful and easy to use, the higher their behavioral intention to enroll in MOOCs in the future. Pointing to the 
course's usefulness students say: "there are many examples in the course", "we can study anywhere", "it improves our English", "we can watch the lecture again", "we don't spend time as in a conventional class"...When talking about the MOOC's perceived ease of use students mention: "the interface is convenient", "there are examples", "the course is clear", "the site is clear".

Results also suggest that the effect of PU was greater than that of PEOU. This finding is not surprising because previous studies have already shown that PU has a stronger effect on technology acceptance than PEOU (e.g., Aharony, 2014c). Our results indicate that students will use MOOCs if they perceive that such usage is beneficial, will help them to study better, and will improve their learning outcomes. Further, they will use MOOCs if they find them friendly, simple and perceive they would not require a lot of effort. If instructors would like their students to adopt MOOCs, they should present to their students MOOCs' usefulness and ease of use, hoping it will encourage their students to enroll in MOOCs within their curriculum. In addition efforts should be made to increase the usability of MOOCs.

$\mathrm{H} 3$ and H4 that focus on learning strategies were not accepted. Results show that neither deep learning strategy nor surface one, were significantly correlated with intended future use of MOOCs. These findings are surprising as we assumed that deep learners will be more motivated to study on a new technological platform, and would like to experience new methods during their learning process. However, an interesting interaction that was revealed in the study showed that, especially among students who were ranked as low in deep learning strategies, the higher they perceive MOOCs' PEOU, the greater their MOOC future use will be. Thus, for those students who are low in deep learning strategy, the perceived ease of use is an important factor in deciding to enroll in a MOOC in the future. This indicates that because they are not high in deep learning, technical variables such as simplicity and friendliness may influence their MOOC future use.

Addressing the two last hypotheses (H5 and H6) that relate to the threat and challenge variables, we see that only H6 was accepted. It was surprising to see that H5 (challenge) was not accepted. However, we see that the more threatened students are the less they will use MOOCs in the future. In other words, the more students perceive the new technological platform that includes a large number of students, and peer assessment as threatening, the less they intend to use MOOCs. This result is comparable with previous studies (Aharony, 2014c; Lazarus, 1991; Lazarus \& Folkman, 1984) suggesting that when respondents view situations as threats, they infer there is a potential danger for their well-being. Instructors should emphasize the usefulness and ease of use of MOOCs, thus, reducing the students' threat level. This will hopefully encourage them to try using MOOCs within their curriculum. Perceived ease of use can be influenced by developing improved MOOCs platforms.

Another interesting finding that was revealed in the current study was that the higher students' academic degree, the higher MOOCs' future use will be. In other words, MA students intend to enroll in MOOCs in the future more than BA students. This finding accompanies previous results in the current study, that address the MA students and showed that the more educated students are, the higher they perceive MOOCs usefulness, the deeper learners they are, and the more challenged they are of MOOCs use. As a whole, findings display a difference between MA and BA students, suggesting that MA students are deeper learners, their intention to use MOOCs in the future is greater, they perceive more the usefulness of MOOCs, and feel more challenged participating in MOOCs.

The qualitative analysis revealed mood changes over time, the feeling of uncertainty was replaced by expressions of confidence. Students felt threatened by the fact that the course was in English at the beginning, but they were content to realize that they are able to cope and overcome this difficulty as the course proceeded. 
In conclusion, the current study found that perceived usefulness and ease of use have major influence on the intention to enroll in a MOOC. Perceived ease of use can be increased by improving the current MOOCs platforms. In order to achieve this, user studies are needed to understand how the platforms are used and what problems users encounter, thus facilitating students' engagement with MOOCs. Perceived usefulness can also be improved by providing content that suits the students' needs, hence increasing students' perceptions about the content's relevance and usefulness.

Findings also reveal that students have different needs and expectations; for example, some of the students were satisfied with the questions that test understanding in the middle of the videos while others were distracted by these questions. In addition, some preferred to read the transcripts while others preferred watching the videos. Therefore the MOOCs platforms should provide multiple options to accommodate these needs.

This study has some limitations. The first is that, in order to gain a broader perspective, it is recommended that a further study that includes a larger number of students who study via the MOOCs be conducted. This study concentrated on a single course, and possible the subject matter of the course and the instructor affects the attitudes. Finally, since the current study focused only on Israeli students, we suggest that in order to have an international perspective towards MOOCs assimilation; the study should be carried out in other countries as well.

\section{References}

Aharony, N. (2009). The influence of LIS students' personality characteristics on their perceptions towards Web 2.0 use. Journal of Librarianship and Information Science, 41(4), 227-241.

Aharony, N. (2014a). The effect of personal and situational factors on LIS students' and professionals' intentions to use e-books. Library \& Information Science Research, 36(2), 106-113. doi:10.1016/j.lisr.2014.01.001

Aharony, N. (2014b). Library and information science students' perceptions of m-learning. Journal of Librarianship and Information Science, 46(1), 48-61.

Aharony, N. (2014c). Factors affecting the adoption of e-books by information professionals. Journal of Librarianship and Information Science. doi: 10.1177/0961000614532120

Alraimi, K. M., Zo, H., \& Ciganek, A. P. (2015). Understanding the MOOCs continuance: The role of openness and reputation. Computers \& Education, 80, 28-38.

Al-Busaidi, K. A. (2013). An empirical investigation linking learners' adoption of blended learning to their intention of full e-learning. Behaviour \& IT 32(11), 1168-1176.

Barnes, S. J., \& Huff, S. L. (2003). Rising sun: iMode and the wireless Internet. Communications of the $A C M, 46(11), 78-84$.

Belanger, Y., \& Thornton, J. (2013). Bioelectricity: A quantitative approach. Duke University's first $M O O C$. Retrieved from

http://dukespace.lib.duke.edu/dspace/bitstream/handle/10161/6216/Duke Bioelectricity_MOOC Fall2 012.pdf

Berns, T. (2004). Usability and user-centered design, a necessity for efficient e-learning! International Journal of the Computer, the Internet and Management, 12(2), 20-25.

Biggs, J. (1987). The Study Process Questionnaire (SPQ): Manual. Hawthorn, Victoria: Australian Council for Educational Research.

Biggs, J. (1993). What do inventories of students' learning process really measure? A theoretical review and clarification, British Journal of Educational Psychology, 63, 3-19.

Blascovich, J. (2008). Challenge and threat. In A. J. Elliott (Ed.), Handbook of approach and avoidance motivation (pp. 431-445). New York, NY: Psychology Press. 
Blascovich, J., Mendes, W. B., Hunter, S. B. \& Lickel, B. (2000). The social psychology of stigma. In T. Heatherton, R. Kleck, \& J. G. Hull (Eds.), Stigma, threat, and social interactions. New York: Guilford Publications, Inc.

Burton-Jones, A., \& Hubona, G. S. (2005). Individual differences and usage behavior: Revisiting a Technology Acceptance Model assumption. ACM SIGMIS Database, 36(2), 58-77.

Carolan, S., \& Magnin, M. (2013). Le MOOC et la motivation. Paper presented at EIAH2013. Retrieved from http://ateliermooceiah2013.files.wordpress.com/2013/05/carolan.pdf

Christensen, G., Steinmetz, A., Alcorn, B., Bennett, A., Woods, D., \& Emanuel, E. (2013). The MOOC phenomenon: Who takes MOOC and why? Retrieved from http://papers.ssrn.com/sol3/papers.cfm?abstract_id $=2350964$

Cheung, R., \& Vogel, D. (2013). Predicting user acceptance of collaborative technologies: An extension of the technology acceptance model for e-learning. Computers and Education, 63, 160-175.

Daradoumis, T., Bassi, R., Xhafa, F., \& Caballe, S. (2013). A review on massive e-learning (MOOC) design, delivery and assessment. Eighth International Conference on P2P, Parallel, Grid, Cloud, and Internet Computing. doi:10.1109/3PGCIC. 2013.37

Davis, F. (1989). Perceived usefulness, perceived ease of use, and user acceptance of information technology. MIS Quarterly, 13(3), 319-339.

de Lera, E., Fernandez, C., \& Valverde, L. (2010). The emotional gap in virtual online environments. In Z. Abas, I. Jung, \& J. Luca (Eds.), Proceedings of Global Learn Asia Pacific 2010 (pp. 67-70). AACE.

de Porto Alegre Muniz, M. I., \& de Moraes, A. (2012). Usability issues in learning management systems (LMS). Work 41, 832-837. doi: 10.3233/WOR-2012-0250-832

Duff, A. (2004). The role of cognitive learning styles in accounting education. Journal of Accounting Education, 22, 29-52.

Ellis, R. A., Goodyear, P., Brillant, M., \& Prosser, M. (2008). Student experiences in problem based learning in pharmacy: Conceptions of learning, approaches to learning and the integration of face to face and on- line activities. Advances in Health Science Education: Theory and Practice, 13(5), 675-692.

Ellis, R. A., Goodyear, P., Calvo, R. A., \& Prosser, M. (2008). Engineering students' conceptions of and approaches to learning through discussions in face-to-face and online contexts. Learning and Instruction, 18(3), 267-282.

Entwistle, N. J. (1977). Strategies of learning and studying: Recent research findings. British Journal of Educational Psychology, 25(3), 225-237.

Fishbein, M., \& Ajzen, I. (1975). Belief, attitude, intention and behavior: An introduction to theory and research. Reading, MA: Addison-Wesley.

Gefen, D., \& Straub, D.W. (1997). Gender difference in the perception and use of e-mail: An extension to the Technology Acceptance Model. MIS Quarterly, 21(4), 389-400.

Glance, D., Forsey, M., \& Riley, M. (2012). The pedagogical foundations of massive open online courses. First Monday Journal. doi:10.5210/fm.v18i5.4350

Grover, S., Franz, P.E., Schneider, E. \& Pea, R.D. (2013). The MOOC as distributed intelligence: Dimensions of a framework for design \& evaluation of MOOCs. Proceedings of the 10th Annual International Conference on Computer Supported Collaborative Learning (CSCL) 2013, Madison, WI.

Islam, N. A. K. M. (2013). Investigating e-learning system usage outcomes in the university context. Computers and Education, 69, 387-399.

Joseph, M. A. I., \& Nath, M. B. (2013). Integration of massive open online education (MOOC) system with in-classroom interaction and assessment and accreditation: An extensive report from a pilot study. $\mathrm{Pa}-$ per presented at Worldcomp 2013, July 22-25, Las Vegas, Nevada. Retrieved from http://weblidi.info.unlp.edu.ar/WorldComp2013-Mirror/p2013/EEE3547.pdf 
Kember, D., Charlesworth, M., Dabies, S., Mackay, J., \& Scott, V. (1997). Evaluating the effectiveness of educational innovations: Using the SPQ to show that meaningful learning occurs. Studies in Educational Evaluation, 23(2), 141-157.

Krippendorff, K. (1980). Content analysis: An introduction to its methodology. Beverly Hills, CA: Sage Publications.

Kuhlthau, C. (1991). Inside the search process: Information seeking from the user's perspective. Journal of the American Society for Information Science, 45(2), 361-371.

Lazarus, R. S. (1991). Emotion and adaptation. New York: Oxford University Press.

Lazarus, R. S. (1993). Coping theory and research: Past, present and future. Psychosomatic Medicine, 55, 234-247.

Lazarus, R. S., \& Folkman, S. (1984). Stress, appraisal and coping. New York, NY: Springer.

Lazarus, R. S., Kanner, A. D., \& Folkman, S. (1980). Emotions: A cognitive-phenomenological analysis. In R. Plutchik \& H. Kellerman (Eds.), Emotion: Theory, research and experience (pp. 189-217). New York: Faculty Press.

Lewis, B. A., MacEntee, V. M., DeLaCruz, S., Englander, C., Jeffrey, T., Takach, E., ... Woodall, J. (2005). Learning management system comparison. In Proceedings of the 2005 Informing Science and IT Education Joint Conference: Flagstaff, AZ, USA, June 16-19. Santa Rosa, California: Informing Science Press. http://www85.homepage.villanova.edu/timothy.ay/DIT2160/LMS/P03f55Lewis.pdf

Liu, Y., Li, H., \& Carlsson, C. (2010). Factors driving the adoption of m-learning: An empirical study. Computers \& Education, 55(3), 1211-1219.

Marton, F., \& Säljö, R. (1976a). On qualitative differences in learning: 1-outcome and process. British Journal of Educational Psychology, 46, 4-11.

Marton, F., \& Säljö, R. (1976b). On qualitative differences in learning: 2-outcome as a function of the learner's conception of the task. British Journal of Educational Psychology, 46, 115-127.

Mastoras, T., Fotaris, P., Politis, A., \& Manitsaris, A. (2005). Designing simplicity: Usability perspectives on learning management systems. WSEAS Transactions on Information Science and Applications, 2 (10), 1731-1738.

Mendes, W. B., Blascovich, J., Hunter, S. B., Lickel, B., \& Jost, J. T. (2007). Threatened by the unexpected: Physiological responses during social interactions with expectancy-violating partners. Journal of Personality and Social Psychology, 92, 698-716.

Miguel, J., Caballe, S., \& Proeto, J. (2013). Providing information security to MOOC: Towards affecting student authentication. $5^{\text {th }}$ International Conference on Intelligent Networking and Collaborative Systems. doi: 10.1109. INCoS.2013.52

Nan, L., Himanshu, V., Afroditi, S., Guillaume, Z., Jan, B., \& Dillenbourg, P. (2014). Watching MOOCs together: Investigating co-located MOOC study groups. Distance Education, 35(2), 217-233, doi: $10.1080 / 01587919.2014 .917708$

Neuendorf, K. (2002). The content analysis guidebook. Thousand Oaks, CA: Sage.

Nielsen, J. (1993). Usability engineering. Massachusetts: Academic Press

Nokelainen, P. (2006). An empirical assessment of pedagogical usability criteria for digital learning material with elementary school students. Educational Technology \& Society, 9(2), 178-197.

Pappano, L. (2012). The year of the MOOC. The New York Times. Retrieved from http://www.nytimes.com/2012/11/04/education/edlife/massive-open-online-courses-are-multiplying-ata-rapid-pace.html?pagewanted $=$ all\& $\mathrm{r}=0$

Park, C. L., \& Folkman, S. (1997). The role of meaning in the context of stress and coping. General Review of Psychology, 2, 115-144. 
Prat-Sala, M., \& Redford, P. (2010). The interplay between motivation, self-efficacy and approaches to studying. British Journal of Educational Psychology, 80(2), 283-305.

Preece, J., Rogers, Y., \& Sharp, H. (2002). Interaction design: Beyond human-computer interaction. Hoboken, NJ: John Wiley \& Sons.

Pretorius, M., \& van Biljon, J. (2010). Learning management systems: ICT skills, usability and learnability, Interactive Technology and Smart Education, 7(1), 30-43.

Rapee, R. M., \& Heimberg, R. G. (1997). A cognitive-behavioral model of anxiety in social phobia. Behaviour Research and Therapy, 35(8), 741-756.

Rozanski, E. P., \& Haake, A. R. (2003). Curriculum and content: The many facets of HCI. Paper presented at the 4th Conference on Information Technology Curriculum on Information Technology Education, Lafayette, IN.

Seery, M. D., Weisbuch, M., Hetenyi, M. A., \& Blascovich, J. (2010). Cardiovascular measures independently predict performance in a university course. Psychophysiology, 47, 535-539.

Siemens, G. (2013). Massive open online courses: Innovation in education? Open Educational Resources: Innovation, Research and Practice, 5, 5-15.

Trigwell, K., \& Prosser, M. (1991). Relating approaches to study and quality of learning outcomes at the course level. British Journal of Educational Psychology, 61, 265-275.

University of Pennsylvania Graduate School of Education, Press Room. (2013, December 9). Penn GSE study shows MOOCs have relatively few active users, with only a few persisting to course end. Retrieved from http://www.gse.upenn.edu/pressroom/press-releases/2013/12/penn-gse-study-showsmoocs-have-relatively-few-active-users-only-few-persisti

Von Stumm, S., \& Furnham, A. F. (2012). Learning approaches: Associations with typical intellectual engagement, intelligence and the Big Five. Personality and Individual Differences, 53(5), 720-723.

Wilson, P., \& Eklund, R. C. (1998). The relationship between competitive anxiety and self-presentational concerns. Journal of Sport and Exercise Psychology, 20, 81-97.

$\mathrm{Xu}, \mathrm{F}$. (2015). Research of the MOOC study behaviour influencing factors. Proceedings of International Conference on Advanced Information and Communication Technology for Education (pp. 18-22). Atlantis Press, Amsterdam, Netherlands, Atlantis Press.

Yang, Y., \& Tsai, C. (2010). Conceptions of and approaches to learning through online peer assessment. Learning and Instruction, 20, 72-83.

Yekutiel, S. (1990). Fathers' and mothers' confrontation with the transition of parenthood. Unpublished Master's thesis, Bar-Ilan University.

Zhou, M. (2016). Chinese university students' acceptance of MOOCs: A self-determination perspective. Computers \& Education, 92-93, 194-203. 


\section{Appendix: MOOC Questionnaire}

\section{Personal Details}

1. Male / Female

2. Age:

3. Education:

\section{Perceived Usefulness (PU) Questionnaire}

Below are statements concerning your attitudes towards MOOCs. Please mark with $\mathrm{X}$ the column which describes your accordance with the following statements

(1=strongly disagree, $5=$ strongly agree).

\begin{tabular}{|c|c|c|c|c|c|}
\hline Statement & 1 & 2 & 3 & 4 & 5 \\
\hline 1. Using MOOCS will help me in the long run & & & & & \\
\hline 2. I believe using MOOCs will improve the learning process & & & & & \\
\hline 3. Using MOOS will contribute to my personal success in the future & & & & & \\
\hline
\end{tabular}

\section{Perceived Ease of Use (PEOU) Questionnaire}

Below are statements concerning your attitudes towards MOOCs. Please mark with X the column which describes your accordance with the following statements ( $1=$ strongly disagree, $5=$ strongly agree).

\begin{tabular}{|c|c|c|c|c|c|c|}
\hline \multirow{2}{*}{\multicolumn{2}{|c|}{ 1. It would be easy for me to become skillful at MOOCs }} & 1 & 2 & 3 & 4 & 5 \\
\hline & & & & & & \\
\hline 2. I think that using MOOCs is very simple & & & & & & \\
\hline 3. I think that generally MOOCs use is simple & & & & & & \\
\hline
\end{tabular}

\section{Learning Strategies}

Listed below are several statements regarding one's general beliefs and attitudes towards the learning process. Please indicate the degree to which you agree or disagree with each statement by marking $X$ the appropriate column of the scale $(1=$ strongly disagree, $5=$ strongly agree).

\begin{tabular}{|c|c|c|c|c|c|}
\hline Statement & 1 & 2 & 3 & 4 & 5 \\
\hline 1. I find that studies cause me a great satisfaction & & & & & \\
\hline 2. I would like to pass the course with minimal learning & & & & & \\
\hline $\begin{array}{l}\text { 3. I find that most of the learning subjects are interesting and I am ready to devote a lot of } \\
\text { time outside class to enrich my knowledge }\end{array}$ & & & & & \\
\hline 4. I don't find any course interesting, thus I do the minimum I can & & & & & \\
\hline 5. I learn things by heart, even if I do not understand them & & & & & \\
\hline 6. I compare the learning process to listening to a good concert or to enjoying a good film & & & & & \\
\hline 7. I find it easier to learn by heart and not to try to understand the whole issue & & & & & \\
\hline 8. I devote a lot of time to learning because I find it very interesting & & & & & \\
\hline 9. In my leisure time I look for further information in reference books & & & & & \\
\hline 10. I think it is enough to have minimal basic understandings in the material & & & & & \\
\hline $\begin{array}{l}\text { 11. I think lecturers should understand that students will not learn material which is not } \\
\text { going to be included in tests }\end{array}$ & & & & & \\
\hline $\begin{array}{l}\text { 12. I usually come to class with some questions, and I expect they will be answered at the } \\
\text { end of the lecture }\end{array}$ & & & & & \\
\hline 13. I read all the additional materials suggested by the lecturer & & & & & \\
\hline $\begin{array}{l}\text { 14. I think the best way to pass the exam is to remember questions that will probably appear } \\
\text { in the exam }\end{array}$ & & & & & \\
\hline
\end{tabular}




\section{Cognitive Appraisal Questionnaire: Threat versus Challenge}

Below are statements concerning your attitudes towards new situations (adopting MOOC). Please mark with $X$ the column which describes your accordance with the following statements $(1=$ strongly disagree; $5=$ strongly Agree).

\begin{tabular}{|l|l|l|l|l|l|}
\hline When you think of MOOC & 1 & 2 & 3 & 4 & 5 \\
\hline 1.The situation stresses me & & & & & \\
\hline 2. The situation seems difficult to me & & & & & \\
\hline 3. The situation threatens me & & & & & \\
\hline 4. The situation will harm me & & & & & \\
\hline 5. You think you can benefit from this situation & & & & & \\
\hline 6. The situation makes me angry & & & & & \\
\hline 7. This situation causes anxiety & & & & & \\
\hline 8 This situation causes certainty & & & & & \\
\hline 9. The situation enables me to show my capacity
\end{tabular}

\section{Biographies}
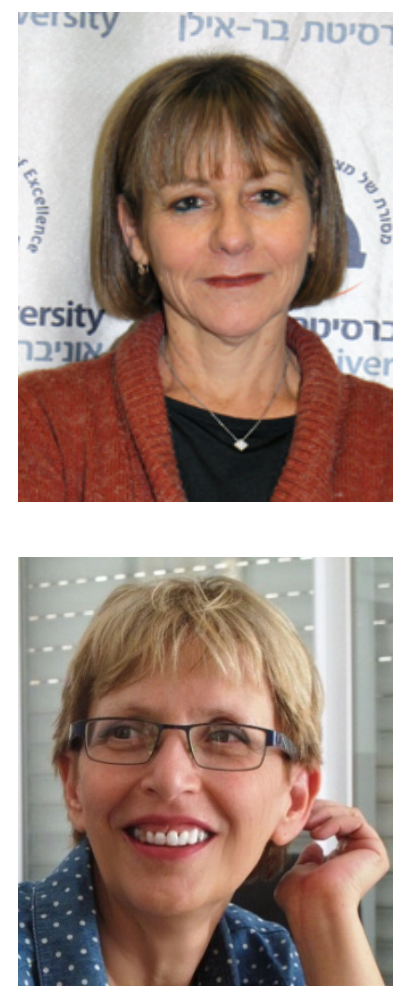

Noa Aharony is a professor at the Department of Information Science of Bar-Ilan University in Israel. She received her PhD in 2003 from the School of Education at Bar-Ilan University (Israel). She is the head of the Information Science Department at Bar-Ilan University (Israel). Her research interests are in education for library and information science, information literacy, technological innovations and the LIS community, and Web 2.0. Prof. Aharony is a member of the editorial boards of Journal of Science, Online Information Review, and IJELLO.

Judit Bar-Ilan is professor at the Department of Information Science of Bar-Ilan University in Israel. She received her $\mathrm{PhD}$ in computer science from the Hebrew University of Jerusalem and started her research in information science in the mid-1990s at the School of Library, Archive and Information Studies of the Hebrew University of Jerusalem. She moved to the Department of Information Science at Bar-Ilan University in 2002. She is a member of the editorial boards of JASIST, Scientometrics, Journal of Informetrics, PLoS ONE, Cybermetrics, and Online Information Review. Her interests include informetrics, information retrieval, Internet research, information behavior and usability. 